\title{
PERCEPÇÃO E CONHECIMENTO NA APRENDIZAGEM INFANTIL A PARTIR DE ESCRITOS DE BENJAMIN
}

\author{
Anita Helena Schlesener
}

\section{RESUMO}

Este artigo desenvolve uma reflexão sobre alguns escritos de Walter Benjamin a respeito da mímesis e da educação. Benjamin coloca em questão a educação burguesa e suas práticas, e reflete sobre a visão da criança, distinta da experiência do adulto. O objetivo é acentuar como a criança realiza seu conhecimento de mundo com o exercício permanente da imaginação, da fantasia e da sensibilidade. Ao brincar a criança reorganiza o mundo e se identifica com ele. A criança não imita o mundo do adulto, mas inventa seu mundo quando brinca. A percepção infantil enquanto um processo de descoberta do mundo tem um aspecto revolucionário se considerada na educação das massas. Benjamin sugere uma pedagogia que não se adapte às exigências do mundo adulto, mas que garanta para criança a realização de sua infância.

PALAVRAS-CHAVE: Educação. Infância. Walter Benjamin.

\section{ABSTRACT}

This work develops a reflection about some writings of Walter Benjamin about mimesis and education. Benjamin place in question the education bourgeois and theirs practices and reflect about children's vision, that be distinguished from adult's experience. The objective is accentuate how the children accomplish his appenticement with exercise of imagination, fantasy an sensitivity. To play means it child to recognize it world and to identify with it. The child does not imitate the adult world, but she invents its world when playing. The childish perception while a discovery process

${ }^{*}$ Professora de Filosofia da UFPR (aposentada) e professora do Mestrado em Educação da UTP - Universidade Tuiuti do Paraná. E-mail: anita.helena@libera.it 
of the world has an aspect revolutionary if considered the fundamental beginning for the education of the masses. Benjamin suggests a pedagogy that does not look to adapt to the requirements of the adult world (of the work and the instrumental reason), but aims at to garantee to the children the accomplishment of its childhood.

HEY WORDS: Education. Childhood. Walter Benjamin.

\section{Introdução:}

$\mathrm{O}$ que Benjamin dizia e escrevia soava como se o pensamento assumisse as promessas dos contos de fadas e dos livros infantis, ao invés de recusá-las e repelí-las em nome de uma infame maturidade (ADORNO, 1998, p. 224-225).

O objetivo desse trabalho é refletir sobre alguns aspectos da percepção e do aprendizado da criança a partir de escritos de Walter Benjamin sobre a mímesis e o processo de cognição infantil. Esta questão tem significativa importância nas reflexões do autor e aparece com frequência a propósito de conceitos básicos para o entendimento de sua filosofia, como sonho, limiar, mito, pedagogia. Identificar as características do processo de cognição infantil nos escritos de Walter Benjamin significa reconhecer que essa reflexão perpassa e esclarece outros conceitos fundamentais para a compreensão da história e da política, dimensões que assume a educação.

As reflexões sobre a capacidade mimética da criança e a crítica às pedagogias que constituíam a base da educação no início do século XX inserem-se na crítica mais ampla da modernidade nas várias características que esta assume, ou seja, na valorização da universalidade da história, na consolidação de um tempo linear que renova e perpetua um estilo de vida resultante de um modo de produção que visa essencialmente a exploração da natureza e dos homens; no âmbito do conhecimento, a universalidade do conceito como medida para avaliar e submeter as singularidades do real e a pluralidade empírica. Conforme acentua Adorno, Benjamin queria "restaurar tudo o que o espírito de acomodação e de autopreservação proíbe 
no prazer, em que os sentidos e o intelecto se cruzam" (ADORNO, 1998, p. 225), isto é, recuperar tudo o que a racionalidade moderna, desde Descartes, havia recusado como fonte de conhecimento, sem cair no irracionalismo, mas propondo um novo paradigma de leitura da história.

Unindo percepção e conceito, os fragmentos benjaminianos mostram um novo método reflexivo, cuja ideia básica é "começar sempre de novo e voltar sempre, minuciosamente, às próprias coisas" (BENJAMIN, 1984, p. 50); trabalho paciente que consiste em desarticular e reconstruir o objeto, as partes e o todo, a fim de liberar os objetos de seus significados comuns e mostrá-los em sua materialidade, para reconfigurá-los em um novo conjunto significativo. Um método que produz uma forma peculiar de ler a história na técnica de montagem de fragmentos como se construísse um mosaico a partir do particular e suas possíveis combinações. Uma leitura que abre vias de alternativas de construção e reconfiguração da realidade, como Penélope a entrelaçar os fios na sua interminável tecelagem ou o fato de recomeçar sempre outra vez, das brincadeiras infantis. Essa é a tarefa do historiador materialista, que precisa mirar-se no trabalho de escavação do arqueólogo ou estabelecer afinidades entre a decifração da história e a paixão do colecionador. Se este põe a sua marca nos objetos, ao retirá-los do contexto do mundo das mercadorias ou da história contínua para reconfigurá-los em sua coleção, o arqueólogo procura reconstruir os significados que se perderam, identificando-os nos restos soterrados e nos rastros deixados no terreno.

Ao historiador cabe subtrair os fatos do tempo linear, revivendo um passado que não se concretizou e que está inserido na atualidade com esse caráter de expectativa frustrada. Assim como o colecionador renova o velho ao dispô-lo em uma nova ordem, por meio de uma abordagem que envolve sua paixão pelos objetos que coleciona, assim também o historiador desprende as imagens das suas conexões mais primitivas ou do seu encadeamento linear contínuo, recuperando-as para a atualidade. Recordar não o que de fato aconteceu, mas o que se perdeu ou fracassou e que não conta na versão dos vencedores, na busca das dimensões longínquas e esquecidas da realidade histórica.

A criança, em suas brincadeiras, recolhe os restos da atividade dos adultos e os transforma em brinquedos ou em elementos de suas coleções 
guardadas em gavetas e caixas. "Uma 'arrumação" aniquilaria "uma obra cheia de castanhas espinhentas - as estrelas da manhã - de folhas de estanho - um tesouro de prata" e tudo o que era possível juntar para inventar a sua imagem do mundo das coisas (BENJAMIN, 1987, p. 124). Refletir sobre o aprendizado e a cognição infantil é um dos modos de Benjamin constatar as contradições que permeiam a estrutura social moderna e criticar uma educação fundada em um ideal de cultura e civilização que a burguesia alimentou a partir de suas conquistas. A realidade da guerra e da violência, geradas no bojo do sistema capitalista no início do século $\mathrm{XX}$, tem repercussões na prática educativa que integra a criança ao mundo adulto, mundo em que imperam determinadas relações de poder e dominação.

Apontar os limites das pedagogias da época, retomar aspectos da percepção e do aprendizado da criança na sua relação com a cor, no gestual da dança e na experiência do teatro, aspectos esquecidos no processo de educação moderna, permite explicitar as relações vividas na modernidade e propor novas perspectivas de aprendizagem. A criança está inserida no social e na história, participa de uma cultura e pode contribuir para modificá-la, à medida que vê o mundo com outros olhos, que não aqueles que direcionam para certas constelações. Com outra maneira de ver a realidade, elas identificam o rosto do mundo naquilo que o adulto descartou como insignificante, o lixo da história. É o que se pretende ao salientar a dimensão estética - mimética - da aprendizagem, para pensar em novas formas de sociabilidade, alternativas à socialização burguesa, que privilegia a racionalidade abstrata e formal, de acordo com os interesses da produção e do consumo; vale dizer, salientar, a dimensão política da educação jamais esquecida por Benjamin.

Mímesis e aprendizagem "As cores da fantasia [...] Para as crianças a cor é uma espécie de percepção inata (as Empfrangene), a expressão da fantasia" (BENJAMIN, 1991a, p. 25).

O diálogo escrito provavelmente entre 1915-16, intitulado $O$ arcoiris - Diálogo sobre a fantasia, que foi considerado perdido até 1977, quando foi encontrado em Roma, entre cartas de Benjamin conservadas por Herbert Blumenthal Belmore, ${ }^{1}$ traz um tema que se desenvolve

${ }^{1}$ Conforme anotações de Benjamin no verso do escrito, o diálogo foi dedicado à 
posteriormente na reflexão sobre a faculdade mimética.

O pretexto do diálogo é o relato de um sonho no qual as cores se apresentavam com tal pureza e esplendor que não podiam ser narradas. Segue-se, então, uma reflexão sobre as cores nas imagens da fantasia, ressaltando o olhar como o sentido que possibilita a identificação com a cor: "Eu própria era cor nessa paisagem" (BENJAMIN, 1991a, p. 20). A mesma observação retorna no fragmento "A visão das cores pela criança", escrito entre 1914-15, no qual se acentua que "O arco-íris é uma límpida imagem infantil". Esta ideia está fortemente ancorada na estética dos românticos, na relação entre a visão infantil das cores e a essência espiritual no infinito da cor. Opondo as cores às formas, Benjamin contrapõe também a percepção infantil fundada numa inquebrantável atividade da fantasia à visão de mundo do adulto que racionaliza e busca o acabamento da substância, a individualidade do tom (BENJAMIN, 1991b, p. 110).

No diálogo $O$ arco-íris a reflexão encaminha-se para a distinção entre a percepção da cor no sonho e na arte: "Por que nas imagens dos pintores nunca se encontram as cores puras e ardentes, as cores dos sonhos?" Entre as distinções, aprofunda-se o significado da fantasia e se explicita a essência da arte, que implica não somente a cor, mas o espaço e a profundidade, que gera a impressão do infinito. As "cores dos pintores são relativas em contraposição às cores absolutas da fantasia. A cor pura existe somente na contemplação" - ou intuição - e só na contemplação há o absoluto. A "cor pictórica é somente um reflexo da fantasia", que se transforma em ação criadora com a mediação de luz e sombra que empobrecem a cor (BENJAMIN, 1991a, p. 21).

A reflexão sobre a arte encaminha-se para a explicitação da percepção da cor como pura expressão da fantasia, com características semelhantes no artista e na criança. Como se acentua também em $A$ visão das cores pela criança, "as cores têm algo de espiritual" e são "a pura expressão da visão do mundo" (BENJAMIN, 1991a, p. 23 e 1991b, p. 110). A referência a Baudelaire, já nesse texto de juventude, principalmente salientando a importância da sensibilidade do artista que desenvolve a fantasia, não só pelo sentido visual, mas pelo gosto e pelo odor, mostram

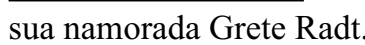


a importância desse tema que retorna em reflexões posteriores. Para Baudelaire, "nada se parece mais com o que chamamos de inspiração do que a alegria com a qual a criança absorve a forma e a cor", isso porque na criança "a sensibilidade ocupa quase todo o seu ser". Aliada ao impulso da curiosidade, a sensibilidade aflora e se expressa no "olhar fixo e animalescamente extático das crianças diante do novo, qualquer que seja ele" (BAUDELAIRE, 1993, p. 223-224).

Também para Benjamin "as cores na vida da criança são a pura expressão da sua pura sensibilidade", meio pelo qual ela própria se orienta no mundo. A percepção infantil das cores traz o sentido da mais alta formação artística, da pureza na qual a criança contempla no conteúdo colorido a fantasia do mundo. A fantasia se concretiza na visão das cores e em inteira relação com o desenvolvimento e a alegria da criança, que a mantém em processo de criação (BENJAMIN, 1991b, p. 110-111). Uma fantasia que não se produz a partir das formas, da ordem das coisas, mas do mundo vivo dos homens no qual a contemplação se traduz em sentimento criador.

O texto $O$ arco-íris - Diálogo sobre a fantasia, inicia uma reflexão sobre a cognição infantil, que merece uma especial atenção por suas implicações estéticas e políticas. Benjamin encontra na percepção infantil uma etapa anterior à adaptação da criança à razão formal e abstrata, algo que o adulto perdeu enquanto imaginação criativa e fantasia. Só as crianças, em sua inocência, conseguem retornar à essência da cor. Para elas, "a cor é uma espécie de percepção inata (as Empfrangene), a expressão da fantasia". A cor expressa a "essência espiritual dos sentidos, o perceber", traduz a beleza imediata, não mediada pelo cânone, que caracteriza a produção do artista. A criança contempla e o artista cria, a criança mergulha na cor, o artista a modifica, combinando-a com a forma, o espaço, a simetria (BENJAMIN, 1991a, p. 25).

Essas observações foram aprofundadas principalmente nos textos que se referem à mímesis, como $A$ doutrina das semelhanças, de 1933, reescrito no mesmo ano com o título Sobre a faculdade mimética. "Essa faculdade tem uma história, tanto no sentido filogenético como ontogenético. No que diz respeito ao último, a brincadeira infantil constitui a escola dessa faculdade". Se a "natureza engendra semelhanças" é "o homem que tem a capacidade suprema de produzi-las" (BENJAMIN, 
1985, p.108), essa capacidade manifesta-se, principalmente, no processo de cognição infantil e, nesse aspecto, na sua vivência das cores.

Em nosso jardim havia um pavilhão abandonado e carcomido. Gostava dele por causa de suas janelas coloridas. Quando, em seu interior, passava a mão de um vidro a outro, ia me transformando. Tingia-me de acordo com a paisagem na janela... Acontecia o mesmo com minhas aquarelas, onde as coisas me abriam seu regaço tão logo as tocava com uma nuvem úmida. Coisa semelhante se dava com as bolhas de sabão. Viajava dentro delas por todo o recinto e misturavame ao jogo de cores de suas cúpulas até que se rompessem. Perdiame nas cores, fosse no céu, numa jóia, num livro. De todo modo, as crianças são sempre presas suas (BENJAMIN, 1987, p. 101).

Brincar com as cores, para a criança, significa reconhecer-se no mundo, identificar-se com as coisas da experiência mimética: "quando misturava as cores, elas me tingiam. Mesmo antes de colocá-las no desenho, me envolviam. Quando, ainda úmidas, imiscuíam-se umas às outras, tomava-as no pincel com tanto cuidado como se fossem nuvens se diluindo". Perceber correspondências, assemelhar-se aos objetos, transportar-se "para dentro do quadro", entrar na "nuvem de cores" (BENJAMIN, 1987, p. 100), fundir-se com a obra no momento da criação, são ecos da experiência que os adultos perderam e que sobrevivem, quem sabe, na criação artística. A mímesis é o modo de aproximação e de interação da criança com o mundo: a percepção visual da criança é imersão nas cores, assim como o brincar é imergir no mundo das coisas, é identificar-se, inicialmente, para em seguida decifrar e se distinguir.

Entretanto, o "dom de reconhecer semelhanças não é mais que um fraco resquício da velha coação de ser e se comportar semelhantemente", ou seja, existem duas maneiras de imitar o mundo: uma que nos faz "semelhantes a modelos de civilidade" e outra que nos identifica ao mundo "às casas, aos móveis, às roupas", e mostra outro significado das coisas ou, como acentua o autor, modifica o mundo e abre o caminho para o seu âmago (BENJAMIN, 1987, p. 98-9). A variedade do colorido do desenho infantil e o modo peculiar da criança apreender as cores em sua transparência, 
mergulhando nelas, é expressão do modo infantil de ver o mundo e romper limites, assim como as brincadeiras e jogos são mecanismos de conhecimento concreto do mundo por meio da mímesis. As brincadeiras, em suas mais variadas modalidades, liberam a fantasia infantil, manifestam a importância da mímesis na apropriação do mundo. "Os jogos infantis são impregnados de comportamento mimético" (BENJAMIN, 1985, p. 108).

A faculdade mimética é o talento de recriar relações, de configurar, de redefinir e repovoar os espaços conforme a fantasia e os desejos; a criança é, muitas vezes, despótica e imperativa, o que pode ser atribuído ao predomínio da sensibilidade na sua percepção do mundo; daí também ser a memória infantil o lugar em que se sobrepõem e interagem os tempos. É no processo de aprendizagem que a criança é introduzida na ordem temporal do adulto, na estrutura temporal linear. É o que acentuam Gebauer e Wulf ao mostrar que a "disciplina exige uma determinada seqüência temporal de atividades", requer "a capacidade laboral e a estruturação e racionalização temporal do fazer" (GEBAUER e WULF, 2004, p. 58).

As observações de Benjamin sobre a percepção visual da criança reaparecem em outros escritos, nos quais há uma recorrência do significado das cores na aprendizagem. Nas observações sobre o livro de Karl, Hobrecker Alte Vergessene Kinderbücher, de 1924, a aprendizagem do mundo por meio das cores se apresenta na leitura dos livros infantis; estes não introduzem "imediatamente os seus leitores no mundo dos objetos, animais e homens", na vida, mas seu significado exterior se define apenas enquanto estabelece uma correspondência com o seu interior. A "interioridade dessa visão está na cor e nela transcorre a vida sonhadora que as coisas vivem no espírito das crianças. Elas aprendem com a cor". É na cor que "a contemplação sensível, desprovida de qualquer nostalgia, está em seu elemento" (BENJAMIN, 1985, p. 240).

$\mathrm{O}$ efeito da imagem colorida é diverso do efeito da figura em preto e branco, embora desempenhem uma função complementar na percepção infantil: a "imagem colorida faz a fantasia infantil mergulhar, sonhadoramente, em si mesma. A gravura em branco e preto, a reprodução sóbria e prosaica, leva-a a sair de si". A figura em branco e preto convida a criança a interagir com a imagem e a iniciar-se na linguagem oral e escrita. Presume-se que as cartilhas da época faziam a relação entre figuras 
e palavras, propondo tal interação. A "imperiosa exigência de descrever contida nessas imagens, estimula na criança a palavra. Mas, assim como ela descreve com palavras essas imagens, ela escreve nelas", penetrando nas imagens (BENJAMIN, 1985, p. 241).

Combinar imagens e palavras, dar espaço à imaginação e à fantasia é uma forma de desenvolver na criança a criatividade, numa aprendizagem que se produz como mímesis. Os contos de fadas eram também instrumentos de aprendizagem mimética, nos quais o sujeito e o objeto não eram pólos opostos, mas interagiam entre si e com a criança:

Em uma história de Andersen aparece um livro cujo preço valia a "metade do reino". Nele tudo estava vivo. "Os pássaros cantavam e as pessoas saíam do livro e falavam". Mas quando a princesa virava a página "pulavam imediatamente de volta, para que não houvesse nenhuma desordem". Delicada e imprecisa, como tanta coisa que ele escreveu, também essa pequena criação passa ao lado daquilo que é mais essencial aqui. Não são as coisas que saltam das páginas em direção à criança que as vai imaginando - a própria criança penetra nas coisas durante o contemplar, como nuvem que se impregna do esplendor colorido desse mundo pictórico (BENJAMIN, 2002, p. 69).

Com seu livro ilustrado entre as mãos, a criança "vence a parede ilusória da superfície" e se esgueira "por entre tecidos e bastidores coloridos, adentra um palco onde vive o conto maravilhoso", num mundo "adornado de cores em que a cada passo as coisas mudam de lugar, a criança é recebida como participante" (BENJAMIN, 2002, p. 69-70). As xilogravuras e as imagens coloridas, no estilo Biedemeier ${ }^{2}$ aliaram imagem e poesia no "mundo de cores ostensivo e auto suficiente" do livro infantil. "Na visão das cores a fantasia em contemplação se dá a conhecer, ao contrário da imaginação criadora, como fenômeno primordial" (BENJAMIN, 2002, p. 77).

A diferença entre fantasia e imaginação criadora se apresenta na

\footnotetext{
${ }^{2}$ Época do romantismo, no século XIX, anos 1820 e 1830, com características específicas na pintura, no mobiliário, na decoração; primava pelo colorido intenso, carmim, laranja, verde brilhante, azul, anil, rosa intensos, que davam um efeito especial às gravuras dos livros infantis.
} 
experiência da mímesis no processo de cognição infantil: como acentua Benjamin, o "próprio corpo na dança, a mão no desenho, reproduz os elementos de sua percepção e os incorpora a si". Porém, essa "capacidade encontra seus limites no mundo das cores: o corpo humano não é capaz de produzir a cor. Ele não corresponde a ela em sentido criativo, mas sim receptivo: através do olho que reverbera em cores". Assim a visão da cor, assim como o "campo sensitivo do olfato e do paladar", traduz-se em correspondências passivas, enquanto a "visão de formas e movimento, audição e fala" expressam "as faculdades das correspondências ativas" (BENJAMIN, 2002, p. 77-78).

Em resumo, retorna, em 1926, uma explicação já apresentada no escrito de 1915, O arco-íris - Diálogo sobre a fantasia: A "cor é a pura expressão da visão do mundo" e, por meio da fantasia, se encontra com o odor e o gosto (BENJAMIN, 1991a, p. 26); também no escrito Visão do livro infantil a diferença entre a fantasia e a imaginação criadora se apresenta na diferença entre a pura percepção da cor e a mediação do cânone: "a cor pura é o meio da fantasia, a pátria de nuvens da criança que brinca, não é o cânone rigoroso do artista que constrói" (BENJAMIN, 2002, p. 79). Apoiando-se na Teoria das Cores, de Goethe, Benjamin acentua a sensibilidade criadora do artista e a "pura intuição da fantasia" presente nas cores (BENJAMIN, 2002, p. 80), reflexão que nos traz à lembrança o diálogo de 1915, também inspirado em Goethe, na qual a mediação entre as cores puras e a pintura se fazia pelo sonho.

Benjamin nos apresenta o livro ilustrado como um instrumento vivo da fantasia infantil, por meio do qual a criança contempla o mundo e o significa. A história ilustrada sugere a invenção de outras histórias, nas quais as "crianças são cenógrafos que não se deixam censurar pelo 'sentido'." Brincando com as palavras "que revolteiam confusamente em meio da brincadeira como sonoros flocos de neve", a criança cria frases e vem "à luz a prosa mais extraordinária", como um "indicador de caminhos" (BENJAMIN, 2002, p. 70).

Essa compreensão da leitura reaparece em um fragmento apresentado em Imagens do Pensamento: existem palavras que, "sem ligação ou conexão entre si, são o ponto de partida de um jogo que, durante a época Biedemeier, tinha grande prestígio". O jogo constituía na tarefa 
de organizar as palavras numa ordem que apresentasse um sentido, num texto o mais curto possível. Para Benjamin esse "jogo fomenta os mais belos achados, sobretudo junto às crianças", para as quais as "palavras ainda são como cavernas" cujos caminhos permitem "curiosas linhas de comunicação". As palavras também sugerem significados variados aos adultos no processo de leitura, tanto que o "leitor culto, ao ler, está à espreita de locuções e palavras e o significado é apenas o pano de fundo do qual descansa a sombra que elas lançam como se fossem figuras em relevo" (BENJAMIN, 1987, p. 271). O texto, diz Benjamin, significava para os romanos aquilo que se tece e quanto mais densa a trama mais belo o texto (BENJAMIN, 1985). Para criança a combinação de imagens e palavras torna-se a base do domínio da linguagem oral e escrita, num jogo de fantasia e prazer, "muito distante da drasticidade embotada" dos pedagogos racionalistas (BENJAMIN, 2002, p. 72).

As características da mímesis no aprendizado infantil vão muito além da simples imitação. A criança não imita o mundo adulto, mas cria o seu, inventando o brinquedo no próprio movimento de brincar que significa sempre libertação, também para o adulto; é possível conhecer "a cena da família reunida sob a árvore de Natal, o pai inteiramente absorto com o trenzinho de brinquedo que ele acabou de dar ao filho, enquanto este chora ao seu lado". Esse ímpeto de brincar não é uma regressão à vida infantil, mas libertar-se "dos horrores do real mediante a sua reprodução miniaturizada". O autor parece referir-se aos horrores da guerra, ampliados com a aplicação de novas tecnologias (BENJAMIN, 2002, p. 85). As crianças criam e adaptam os brinquedos às brincadeiras; e é por meio dos jogos que se formam os hábitos, os quais guardam a imagem da brincadeira. A essência do brincar "não é 'fazer como se', mas 'fazer sempre de novo", transformando em hábito uma experiência inicialmente devastadora (BENJAMIN, 1985, p. 253).

Como acentua Susan Buck-Morss, a "cognição das crianças investia-se de poder revolucionário porque era tátil, e daí ligada à ação, e porque em vez de aceitar o sentido dado das coisas, as crianças conheciam os objetos ao fazê-los e usá-los criativamente". A aprendizagem acontecia pela liberação de "novas possibilidades de significado". O processo de educação escolar na sociedade burguesa "suprimiu essa atividade: 
papaguear de volta a resposta 'correta', olhar sem tocar, resolver problemas 'na cabeça', sentar passivamente", eram comportamentos que limitavam as possibilidades de criação da criança (BUCK-MORSS, 2002, p. 316). Essa dimensão política da educação é a base da crítica benjaminiana à pedagogia da época. As observações sobre as cartilhas e o ensino escolar são acompanhadas de severas críticas à pedagogia racionalista e seu rigorismo, sugerindo a sua total incompreensão da percepção infantil.

A crítica à pedagogia moderna

Em todos os âmbitos - e a pedagogia não constitui nenhuma exceção-o interesse pelo "método" é um posicionamento genuinamente burguês, a ideologia do "continuar a enrolar" e da preguiça (BENJAMIN, 2002, p. 112-3).

O que se depreende dos escritos sobre a cognição infantil é que essa possui uma dimensão estética que é ignorada por toda a pedagogia dos séculos XVIII e XIX. Existem vários aspectos a serem salientados e iniciamos pela crítica às características que assumiu o Iluminismo a partir de uma determinada leitura de Rousseau. Na resenha dedicada ao livro de Hobrecker as críticas se voltam a uma pedagogia na qual "os filantropos punham à prova o seu grande programa de remodelação da humanidade": "se o homem é por natureza piedoso, bom e sociável, deve ser possível fazer da criança, ente natural por excelência, um ser supremamente piedoso, bom e sociável". Essa influência culminou, no livro infantil, em conteúdo "edificante e moralista", o que tornou a cartilha "uma simples variante deísta do catecismo e da exegese". Como exemplo, a Obra elementar de Basedov: ao lado de um "didaticismo universal" que "procurava mostrar a utilidade de todas as coisas - desde a matemática até a arte de equilibrar-se numa corda - havia histórias de moralismo tão radical que beiravam (não de todo involuntariamente) o cômico" (BENJAMIN, 1985, p. 236-7).

Aidentificaçãodomoralismonos livrosinfantis pode seracompanhada do questionamento levantado por Benjamin, já em 1913, sobre a possibilidade do ensino de moral e a finalidade da educação ética. Colocando-se no terreno da filosofia kantiana, o autor identifica uma "antinomia da educação ética" que pode ser "um aspecto particular de uma antinomia geral", ou seja, a 
impossibilidade de atingir "a vontade ética enquanto tal", visto que "o processo de educação ética contradiz, por princípio, toda racionalização e esquematização", não tendo "nenhuma afinidade com o ensino didático". O problema está no fato que este representa "o instrumento de educação racionalizado" (BENJAMIN, 2002, p. 14).

Essa evidência não implica uma defesa do irracionalismo nem o decreto da impossibilidade de uma educação ética, mas o fato que o ensino da moral incide em uma prática moralista determinada pela influência de vários elementos, tais como a prevalência da legalidade, as concepções psicológicas e, principalmente, a realidade da dominação burguesa. A crítica à pedagogia da época encaminha-se para mostrar que o ensino de moral tem um significado enquanto supera o moralismo e possa constituir-se na "transição para um novo ensino de História, no qual também o presente encontre a sua inserção histórico cultural” (BENJAMIN, 2002, p. 19).

Além do moralismo outro equívoco é a ideia de que as crianças são seres tão diferentes dos adultos, que estes "precisam ser particularmente inventivos se quiserem distraí-las", o que gerou uma atividade pedagógica voltada a "produzir objetos - material ilustrativo, brinquedos ou livros supostamente apropriados às crianças". Os pedagogos não se dão conta de dois aspectos essenciais: 1) que as crianças criam os seus próprios brinquedos e que "a terra está cheia de substâncias puras e infalsificáveis, capazes de despertar a atenção infantil"; 2) que as crianças são inteligentes e exigem "dos adultos explicações claras e inteligíveis, mas não explicações infantis"; a "criança aceita perfeitamente coisas sérias, mesmo as abstratas", desde que sejam honestas e espontâneas (BENJAMIN, 1985, p. 236-237).

A abordagem cognitiva do mundo pela criança tem como base a percepção visual e tátil, que poucos na pedagogia souberam valorizar. "Nenhum pensador moderno, com a exceção de Jean Piaget, levou as crianças tão seriamente como o fez Benjamin para desenvolver uma teoria da cognição" (BUCK-MORSS, 2002, p. 313). Nas reflexões sobre o mundo da criança a partir da análise dos livros infantis, dos jogos e brincadeiras vislumbra-se a possibilidade de uma nova pedagogia, em confronto com a educação burguesa. As aproximações que Buck-Morss faz entre Benjamin e Piaget são interessantes para compreender os descaminhos da pedagogia moderna: 
Piaget e Benjamin concordavam que a cognição infantil era um estágio de desenvolvimento tão completamente superado que para o adulto ele aparecia quase como inexplicável. Piaget se limitava a ver o pensamento da criança desaparecer. Os valores em sua epistemologia ficavam inclinados para o lado adulto do espectro. Seu pensamento reflete, no eixo do desenvolvimento ontogenético, a suposição da história-como-progresso que Benjamin considerava a marca da falsa consciência burguesa. Predizivelmente, o interesse próprio de Benjamin não se dirigia ao desenvolvimento seqüencial das etapas da razão formal, abstrata, mas àquilo que se perdia no caminho (BUCKMORSS, 2002, p. 314).

Para Piaget tratava-se de trazer a criança para os limites da razão, desenvolvendo seu raciocínio e abstração: nos "testes de Piaget, o jogo fantástico da criança, a constituição de mundos meramente possíveis eram provavelmente registrados como erro cognitivo", ou seja, Piaget "ignorava a cognição mimética" (BUCK-MORSS, 2002, p. 315). Para Benjamin era precisamente essa a perspectiva que interessava, a expressão e o impulso criativo da criança enquanto modo de conhecimento e de apropriação do mundo, a capacidade de descobrir uma outra ordem das coisas por meio da brincadeira.

$\mathrm{O}$ que Benjamin salientava como perda era precisamente o que a pedagogia burguesa não reconhecia importante no processo educativo, os dados da percepção infantil enquanto um processo de conhecimento do mundo baseado na mímesis, na faculdade de fazer correspondências sensíveis. Essa percepção faz a criança buscar no mundo das coisas os seus brinquedos, retirados de "qualquer lugar de trabalho onde visivelmente transcorre a atividade sobre as coisas". A criança sente-se atraída pelos resíduos, que surgem "na construção, no trabalho de jardinagem ou doméstico, na costura ou na marcenaria", resíduos que colocam uma nova relação entre si para criar um "pequeno mundo de coisas" (BENJAMIN, 1987, p. 18-19).

Assim também os contos de fadas, ao narrarem um tempo indeterminado, permitem abordar os elementos da narrativa como se fossem resíduos que podem mostrar um outro rosto das coisas; a riqueza 
de conteúdo dos contos de fadas está precisamente na sua composição e na possibilidade de brincar com eles, como se brinca com um mosaico recompondo as peças e formando novas figuras. Para a criança os contos são instrumentos de conhecimento que permitem transitar por lugares inusitados, sentir aromas, mergulhar no encantamento das figuras, interagir com os personagens, identificar-se com eles para daí sair, criar um novo significado para o mundo das coisas.

De 1929 em diante os escritos sobre a percepção infantil aliam a dimensão estética com a dimensão política da aprendizagem, estendendose na crítica à pedagogia burguesa, contraposta às experiências educativas realizadas na União Soviética. São desse período os textos: Programa de um teatro infantil proletário e Uma Pedagogia Comunista. O primeiro reflete sobre o trabalho realizado por Asja Lacis na Rússia e o segundo resenha o livro de Edwin Hoernle, Questões fundamentais da educação proletária, publicado em Berlin, em 1929.

A crítica aos pressupostos da pedagogia burguesa, cujos pólos são a psicologia e a ética, salienta que mesmo as forças ativas que se apresentam nas teorias "nada podem fazer contra o fato de que a maneira de pensar da burguesia, aqui como em todos os âmbitos, está cindida de uma forma não dialética e rompida interiormente". Tal cisão se apresenta nos dois objetivos centrais da pedagogia, que esta pretende adaptar: a "natureza do educando: psicologia da infância e da adolescência" e a "meta da educação: o homem integral, o cidadão". Trata-se de uma cisão que aborda o indivíduo como ser isolado, isto é, a "sociedade burguesa hipostasia uma essência absoluta da infância", da mesma forma que a "hipostasia uma essência igualmente absoluta do ser humano ou do cidadão" (BENJAMIN, 2002, p. 121-2). Essa perspectiva idealista, bem como a ausência de uma visão abrangente da realidade educativa, levam ao fracasso da pedagogia.

A diferença fundamental da perspectiva burguesa e da proletária está em que a "burguesia encara a sua prole enquanto herdeiros" e os deserdados "a encaram enquanto apoio, vingadores ou libertadores"; situação que gera "conseqüências pedagógicas incalculáveis". Se a pedagogia burguesa concentra-se no indivíduo e na família, a pedagogia proletária aborda a criança no seu contexto social e político, isto é, não considera apenas a sua natureza infantil, mas também o seu pertencimento a uma classe. A situação 
de classe "penetra-a desde o primeiro instante, já no ventre materno, como a própria vida" e seu processo educativo consiste em "aguçar desde cedo, na escola da necessidade e do sofrimento, sua consciência", que se transforma em consciência de classe (BENJAMIN, 2002, p. 122). Cabe acentuar que a pedagogia burguesa e as práticas educativas apresentam um significado político oculto, assinalado por Hoernle:

Será que escola primária e profissionalizante, militarismo e Igreja, associações de juventude e escoteiros seriam, em sua função oculta e exata, outra coisa senão instrumentos de uma instrução antiproletária dos proletários? A essas instituições contrapõe-se a educação comunista, seguramente não de maneira defensiva, mas sim enquanto uma função da luta de classes (BENJAMIN, 2002, p. 123).

Nessa senda, a educação comunista precisa orientar-se pelo universalismo do trabalho e uma disposição universal para a ação, mobilizando todas as energias para a transformação social revolucionária. Esse é o princípio fundamental para a educação das massas (BENJAMIN, 2002, p. 125). A abordagem das diferenças entre a pedagogia burguesa e a comunista se completa com a explicitação do significado do teatro no aprendizado da criança.

Nas reflexões sobre o teatro a percepção infantil torna-se a base de uma nova pedagogia: o "teatro infantil proletário é para a criança proletária o lugar de educação dialeticamente determinado", tanto por suas possibilidades de formação da consciência crítica quanto pela essência da ação que possibilita: no teatro "realidade e jogo se fundem para as crianças, imbricam-se tão intimamente que sofrimentos encenados podem converter-se em sofrimentos autênticos" (BENJAMIN, 2002, p. 113-114).

A abordagem do aprendizado nessa forma de teatro é completamente diferente da abordagem burguesa; as encenações não visam uma conclusão, mas antes a colocar e a resolver tensões do trabalho coletivo, que "são os verdadeiros educadores". Não há também a preocupação de um diretor "influir sobre as crianças, de maneira imediata, enquanto " personalidade moral"; o que conta são os "conteúdos, tarefas, eventos. A coletividade das próprias crianças encarrega-se de executar os inevitáveis ajustes e 
correções morais" no conjunto do trabalho coletivo (BENJAMIN, 2002, p. 114-115).

$\mathrm{Na}$ experiência do teatro infantil russo Benjamin reconhece o processo de inserção da criança no trabalho coletivo. A "criança vive em seu mundo como ditador", ou seja, ela precisa ser educada, mas com uma nova educação que implique troca e reconhecimento da diferença, não imposição. O gesto infantil em geral "significa uma ordem e um sinal" que, por meio da observação, o diretor procura reconhecer e libertar "do perigoso reino mágico da pura fantasia e conduzi-los à sua execução nos conteúdos”. Nesse aprendizado realizado nas várias oficinas, a criança desenvolve as diferentes formas de expressão que são básicas para o teatro: pintura, recitação, música, dança e improvisação, esta sendo central no processo de aprendizagem, porque é com ela que aflora a capacidade mimética. Da improvisação "emergem os sinais, os gestos sinalizadores" e o teatro é precisamente "a síntese desses gestos, pois tão somente a encenação se manifesta de maneira inesperada e única", o gesto infantil tem nela seu autêntico espaço (BENJAMIN, 2002, p. 116).

Essa nova pedagogia "demonstra a sua superioridade ao garantir às crianças a realização de sua infância" (BENJAMIN, 2002, p. 117). Trata-se de reconhecer a especificidade da criança na qualidade de suas fantasias, na fertilidade de sua imaginação, na criatividade implícita no sonho que, ao contrário da racionalidade instrumental do adulto, abre a possibilidade de uma nova compreensão das coisas e um novo ordenamento do mundo. $\mathrm{Na}$ explicitação do significado do teatro no aprendizado infantil Benjamin parece identificar a possibilidade de concretizar os objetivos da terceira Tese contra Feuerbach, na qual Marx se refere à necessidade de educar o educador:

A encenação é a grande pausa criativa no trabalho educacional. Ela representa no reino das crianças aquilo que o carnaval representava nos antigos cultos. O mais alto converte-se no mais baixo de todos e assim como em Roma, nos dias saturnais, o senhor servia o escravo, assim também as crianças sobem ao palco durante a encenação e ensinam e educam os atentos educadores. Novas forças, novas inervações vêm à luz, das quais frequentemente o diretor jamais teve qualquer vislumbre durante o trabalho (BENJAMIN, 2002, p. 118). 
Esse belíssimo texto dá um novo significado à aprendizagem e mostra como a criança, ao encenar, entrega-se à ação e libera sua fantasia, realizando sua infância na brincadeira. Os gestos, a encenação, tornam-se impulso criativo e concretização da capacidade mimética; essa experiência apresenta uma força revolucionária sem precedentes, porque mostra precisamente que "não é a propaganda de idéia que atua de maneira verdadeiramente revolucionária", mas sim "o sinal secreto do vindouro, o qual fala pelo gesto infantil" (BENJAMIN, 2002, p. 118-119 - grifo do autor).

A expressão mimética na modernidade? "O mundo perceptivo da criança está marcado por traços da geração anterior e se confronta com eles; o mesmo ocorre com suas brincadeiras" (BENJAMIN, 1985, p. 250).

A criança, como o jovem que ainda não se adaptou às exigências do mundo adulto - do trabalho e da razão instrumental -, está aberta à recepção das semelhanças sensíveis e sua formação produz-se como aprendizado - e criação - do mundo. Assim, a expressão mimética e lúdica constitui-se como o gérmen do novo que se contrapõe ao modo de vida do adulto, adaptado às condições do mundo regido pelo modo de produção e de representação modernos.

Observar o comportamento das crianças permite identificar um processo de cognição baseado no reconhecimento de semelhanças, cujas características se alteraram na vida do adulto. A experiência da semelhança modificou-se no curso da história: "com a passagem dos séculos a energia mimética, e com ela o dom de apreensão mimética, abandonou certos espaços" ocupando outros (BENJAMIN, 1985, p. 109). No adulto a capacidade mimética encontra outras formas de manifestação, principalmente na mais significativa que é a linguagem, que "não é um sistema convencional de signos", mas a expressão de significados essenciais, apresentados não mais de modo sensível, mas não sensível, fato que pode ser identificado tanto na fala quanto na escrita ou na relação entre ambas (BENJAMIN, 1985, p. 110-111). A via seguida por Benjamin para demonstrar essa migração da faculdade mimética para a linguagem é refletir sobre a essência da língua a partir das teorias onomatopaicas e o seu desdobramento na comparação de línguas diferentes; ordenando as palavras em torno de um mesmo significado evidencia-se a relação de semelhança não sensível. É esta que estabelece a ligação entre a palavra 
oral e o objeto, a "imagem escrita das palavras ou letras com o significado ou com a pessoa nomeadora". O elo entre a palavra escrita e falada é o menos sensível de todos; a escrita transformou-se, "ao lado da linguagem oral, num arquivo de semelhanças, de correspondências extra-sensíveis" (BENJAMIN, 1985, p. 111). No curso da história, porém, os homens esqueceram desse elo, da dimensão mágica da linguagem oral e escrita, deixando de reconhecer semelhanças não sensíveis para concentrar-se apenas na dimensão semiótica da linguagem.

Pensemos nas novas dimensões que assumiu a linguagem na modernidade com a fotografia, o cinema e as artes em geral. A capacidade mimética está latente e as possibilidades de sua expressão em novas formas de percepção geradas por novas tecnologias são grandes. As reflexões de Benjamin acentuam tanto a migração da faculdade mimética para a linguagem quanto o surgimento de novas formas da faculdade mimética, mediadas pelos instrumentos de comunicação. Já no início do século XX Benjamin reconhece que o "cinema realizou numa década deslocamentos que duraram séculos no mundo das letras". A máquina fotográfica amplia a visão humana e a câmera cinematográfica "abre, pela primeira vez, a experiência do inconsciente ótico, do mesmo modo que a psicanálise nos abre a experiência do inconsciente pulsional" (BENJAMIN, 1985, p. 184189). A partir da aplicação das novas tecnologias no campo da arte e da vida social, forma-se uma nova percepção do mundo e abre a possibilidade de uma nova cognição e aprendizado mimético. Os "múltiplos aspectos que o aparelho pode registrar da realidade situam-se em grande parte fora do espectro de uma percepção sensível" (BENJAMIN, 1985, p. 190); o cinema redefine o espaço à medida que o fragmenta e intensifica o tempo, à medida que o expande ou desacelera, gerando uma nova percepção espaçotemporal que se assemelha ao mundo dos sonhos.

Essa nova experiência dos movimentos, do espaço e do tempo pode desenvolver a capacidade mimética, de tal modo que Benjamin se entusiasma com as possibilidades do cinema no aprendizado das massas: o cinema apresenta uma técnica emancipada que "se confronta com a sociedade moderna sob a forma de uma segunda natureza, não menos elementar que a da sociedade primitiva", natureza que "o homem inventou, mas há muito não controla" e diante da qual "somos obrigados a aprender, 
como outrora diante da primeira. Mais uma vez a arte põe-se a serviço desse aprendizado". O "filme serve para exercitar o homem nas novas percepções e reações exigidas por um aparelho técnico, cujo papel cresce cada vez mais em sua vida cotidiana" (BENJAMIN, 1985, p. 174).

As novas tecnologias têm um significado no contexto da produção capitalista e, enquanto fruto de uma determinada racionalidade instrumental, alienam o homem em si e sua realidade social e política. Benjamin, entretanto, vislumbrava uma outra dimensão, estética e política, como meio de renovar a capacidade mimética: as "novas técnicas miméticas podem instruir o coletivo a empregar essa capacidade efetivamente, não só como defesa contra o trauma da industrialização", mas para "reconstruir a capacidade para a experiência desarticulada por esse processo" (BUCKMORSS, 2002, p. 322).

O processo de aprendizagem da criança exige do adulto, como na encenação, observar e reconhecer os sinais para trazer a criança do mundo mágico para novas vias de leitura e produção de significados; o cinema, por sua vez, se apresenta ao adulto como o meio lúdico de releitura de sua realidade, à medida que possibilita o exercício de uma nova percepção do mundo. Até certo ponto as especificidades da cognição infantil relacionam-se com a capacidade de reler a história, de reinterpretar o passado para a construção de um futuro diferente daquele implícito na realidade social e política da modernidade; esse é o desafio que se apresenta ao historiador materialista.

Como a criança seleciona pedras, retalhos, restos do trabalho para fazer suas coleções, o historiador materialista precisa retirar os fatos de uma ordem causal e contínua para reconfigurá-los em nova constelação, na qual assumem novo sentido, porque o passado está no presente para ser explicitado em significados perdidos no esquecimento. Faz-se necessário rearticular passado e presente para que apareçam outros sentidos, assim como é importante questionar a pedagogia para revigorar a educação e dar-lhe um significado revolucionário. A dimensão política da educação, como acentua Buck-Morss, está em "a história cultural fica no centro de uma educação de classe" e toda atividade educativa precisa proporcionar o "acesso à práxis" (BUCK-MORSS, 2002, p. 344). 


\section{Conclusão:}

Os escritos de Benjamin circunscrevem-se nos limites da realidade do século XX, mas apresentam elementos importantes para refletir sobre a realidade presente visto que alguns dos problemas evidenciados por seus escritos recrudesceram e tomaram proporções gigantescas no mundo contemporâneo. No contexto da pedagogia as reflexões sobre a percepção e a cognição infantil permitem propor novos caminhos de aprendizagem: a mímesis apresenta-se como criação e reconhecimento da identidade, tendo como base o exercício da imaginação, da fantasia e da sensibilidade. Tratase de uma aprendizagem que é essencialmente lúdica, pela qual a criança reconhece semelhanças e faz comparações, inicia o desenvolvimento de sua reflexão crítica. Mais que imitação, a mímesis permite comparar e reconhecer-se na cultura, exercitando a expressão corporal e a percepção sensível para estabelecer correspondências, analogias, bem como reconhecer as tensões entre opostos e contraditórios para a possibilidade de compreensão mais abrangente da realidade.

A dimensão política dessa pedagogia apresenta-se principalmente na acentuação de mecanismos de aprendizagem que não são reconhecidos como tal na pedagogia burguesa, criticada por Benjamin, visto que a educação na sociedade moderna visa inserir o indivíduo no processo produtivo e nos fundamentos da racionalidade instrumental. A dimensão estética revela-se na valorização da percepção sensível e na expressão corporal, que fazem da dança e do teatro instrumentos privilegiados de aprendizagem.

Finalmente, essa abordagem da educação acena com novas vias de leitura e produção de significados que possibilitam tanto concretizar as potencialidades que a criança oferece na sua criatividade e imaginação quanto criar novas significações do mundo; com isso, visa-se ultrapassar os limites restritos da racionalidade instrumental e reinterpretar a história, a fim de descobrir as possibilidades de um futuro diferente daquele implícito na realidade social e política da modernidade. 


\section{Referências}

ADORNO, Theodor, W. Caracterização de Walter Benjamin. In: Prismas. São Paulo: Ática, 1998.

BAUDELAIRE, Charles. O artista, homem do mundo, homem das multidões e criança. In: BAUDELAIRE, Charles. Obras Estéticas Filosofia da imaginação criadora. Petrópolis: Vozes, 1993.

BENJAMIN, Walter. Origem do Drama Barroco Alemão. São Paulo: Brasiliense, 1984.

Obras Escolhidas II Rua de Mão única. São Paulo: Brasiliense, 1987.

Obras Escolhidas - Magia e Técnica, Arte e Política. São Paulo: Brasiliense, 1985.

Reflexões sobre a criança, o brinquedo e a educação. São Paulo: Duas Cidades, 2002. ed. 34.

Der Regenbogen. Gespräch über die Phantasie. Gesammelte Schriften VII, 1 (Nachtrage). Frankfurt a.M. : Suhrkamp Verlag, 1991a.

Die Farbe vom Kinde aus betrachtet. Gesammelte Schriften VI (Fragmente Autobiographische). Frankfurt a.M. : Suhrkamp Verlag, 1991b.

BUCK-MORSS, Susan. Dialética do Olhar. Walter Benjamin e o Projeto das Passagens. Belo Horizonte: Ed. UFMG/Argos, 2002.

GEBAUER, Günter e WULF, Cristoph. Mimese na Cultura. São Paulo: Annablume, 2004. 